\title{
Histological types of malignant mesothelioma and asbestos exposure
}

\author{
W E WRIGHT' ${ }^{1}$ AND R P SHERWIN ${ }^{2}$ \\ From the Department of Preventive Medicine $e^{1}$ and Pathology ${ }^{2}$, University of Southern California School of \\ Medicine, Los Angeles, California 90033, USA
}

ABSTRACT The Los Angeles County Cancer Surveillance Program abstracts hospital pathology records on almost all cases of cancer occurring in the county. Those cases of pleural and peritoneal mesothelioma that occurred between 1972 and 1978 were identified. Occupational histories were obtained from interviews, and the histopathology of the tumours was reviewed by a member of a mesothelioma reference panel who was unaware of the exposure histories. The relation of asbestos exposure to the three histological types of mesothelioma (epithelial, mesenchymal, and mixed) was studied among the 29 cases for whom occupational histories were available and who were also considered to have histopathology consistent with mesothelioma. The proportion of cases exposed to asbestos was high for both the epithelial $(11 / 17,65 \%)$ and mixed histological types $(6 / 11,55 \%)$. The single case of mesothelioma classified as a mesenchymal type was also exposed to asbestos. Cases who had worked in shipyards were represented in each of the three groups. In cases who had worked in asbestos production and manufacture an exclusively epithelial type of tumour was observed. In cases who had worked as insulators or in heating trades the histological type was predominantly (3/4) mixed. These data do not support the hypothesis that any specific histological type of mesothelioma is especially related to asbestos exposure.

The association of malignant pleural and peritoneal mesotheliomas with asbestos exposure is well recognised. ${ }^{1-3}$ In most reports between $40 \%$ and $80 \%$ of people with these tumours have had occupational or domestic exposure to asbestos. ${ }^{4}$ Among people who are heavily exposed to asbestos at work about $8 \%$ of deaths are related to mesothelioma. ${ }^{4}$

The histological pattern of these tumours varies and three main types have been described: epithelial, mesenchymal, and mixed. ${ }^{5}$ In most case series about half the tumours have an epithelial histological pattern. ${ }^{6}$ Some investigators have reported that asbestos exposure is most common in people with mesotheliomas of the mixed type and is infrequent in people whose tumours have the epithelial histology. It has been suggested that this difference may help to distinguish mesotheliomas related to asbestos from those that are not. We have studied cases of mesothelioma diagnosed by pathologists in Los Angeles County and describe here the relationship

Received 22 August 1983. Accepted 26 September 1983 of the histological types of mesothelioma to asbestos exposure.

\section{Methods}

Cases of mesothelioma from ICD-0 (1976) sites 163 (pleural) and 158 (peritoneal), excluding benign mesotheliomas, first diagnosed by pathologists in Los Angeles County between 1972 and 1978, were gathered using the Los Angeles County Cancer Surveillance Program, a population based cancer registry. ${ }^{8}$ Cases were identified from hospital pathology records and from the death certificates of Los Angeles County residents.

Pathology slides and paraffin blocks for each case were requested from the pathology department of each hospital at which a case was diagnosed. These materials were examined and classified by a member (RPS) of the UICC US Mesothelioma Reference Panel. No clinical or exposure information was available to the pathologist. Each case for which tissue was received was classified into the five standard categories used by the mesothelioma panel, and 
these categories were reduced to two major groups:

(1) Diagnosis of mesothelioma more likely than not, and

(2) Diagnosis other than usual pleural or peritoneal mesothelioma favoured or established.

Cases with inadequate material for review-for example, cell blocks, needle biopsies-were excluded. The gross and microscopic characteristics favouring an interpretation of mesothelioma or other cancers are described elsewhere. ${ }^{9}$ The type of histology (epithelial, mesenchymal, or mixed) was recorded for those cases for which the diagnosis of mesothelioma was considered to be more likely than not.

A trained interviewer contacted the cases or their nearest living relative and conducted telephone interviews using a questionnaire that included a chronological occupational history. The occupational histories were assessed for the likelihood of asbestos exposure by one of the authors (WEW) who was unaware of the pathological diagnosis or the histopathology of the cases. Each job was assigned to a category that reflected likelihood of exposure to asbestos. ${ }^{10} 11$ The categories were:

(A) Occupations established to represent likely asbestos exposure ( 1 insulation, 2 asbestos production and manufacture, 3 heating trades, 4 shipyards, 5 construction industry) and

(B) All other occupations.

The cancer surveillance program collected 191 cases of mesothelioma that occurred between 1972 and 1978. A detailed description of these cases has been published.9 ${ }^{9}$ Both histopathological and interview information was available for 118 of the 191 cases $(62 \%)$. Twenty nine of these 118 cases $(25 \%)$ were considered to have histological features that were more likely to represent mesothelioma than not. These cases are the subject of the present study.

\section{Results}

Table 1 shows the proportion of cases of mesothelioma exposed to asbestos according to histological type of tumour. The proportion of cases exposed to asbestos is high for both the epithelial $(11 / 17,65 \%$ for men and women combined) and the mixed histological types $(6 / 11,55 \%$ for men and women combined). Table 2 shows the jobs likely to entail exposure to asbestos according to histological type of tumour. Jobs in asbestos production and manufacture were found only among those people with epithelial mesotheliomas (5 of 11 exposed cases). Work in heating trades ( 2 of 6 exposed cases) and insulation ( 1 of 6 exposed cases) was found in people with mesotheliomas of the mixed type. Shipyard work was represented in the occupational histories of cases with all histological types (4 of 11 exposed epithelial mesotheliomas, 1 of 1 exposed mesenchymal mesothelioma, and 3 of 6 mixed type mesotheliomas). Asbestos exposure was more common in cases considered likely to be mesothelioma (62\%) than in those in which another diagnosis was favoured (52\%).

Table 1 Histological types of mesothelioma in relation to asbestos exposure

\begin{tabular}{lccc}
\hline Histological type & No of cases & No of cases exposed to asbestos & Percentage of cases exposed to asbestos \\
\hline Men: & 13 & 10 & 77 \\
$\quad$ Epithelial & 1 & 1 & 100 \\
Mesenchymal & 9 & 6 & 67 \\
Mixed & & & \\
Women: & 4 & 1 & 25 \\
Epithelial & 0 & 0 & 0 \\
Mesenchymal & 2 & 0 & 0 \\
Mixed & 29 & 18 & 62 \\
Total & & & \\
\hline
\end{tabular}

Table 2 Histological types of mesothelioma in relation to jobs

\begin{tabular}{|c|c|c|c|c|c|c|c|}
\hline \multirow[t]{2}{*}{ Histological type } & \multicolumn{5}{|c|}{ No of cases having jobs with likely exposure to asbestos } & \multirow[b]{2}{*}{ Other jobs* } & \multirow[b]{2}{*}{ Total } \\
\hline & Insulation & Heating trades & $\begin{array}{l}\text { Asbestos } \\
\text { production } \\
\text { and } \\
\text { manufacture }\end{array}$ & Shipyards & Construction & & \\
\hline $\begin{array}{l}\text { Epithelial } \\
\text { Mesenchymal } \\
\text { Mixed } \\
\text { Total }\end{array}$ & $\begin{array}{l}0 \\
0 \\
1 \\
1\end{array}$ & $\begin{array}{l}1 \\
0 \\
2 \\
3\end{array}$ & $\begin{array}{l}5 \\
0 \\
0 \\
5\end{array}$ & $\begin{array}{l}4 \\
1 \\
3 \\
8\end{array}$ & $\begin{array}{l}1 \\
0 \\
0 \\
1\end{array}$ & $\begin{array}{r}6 \\
0 \\
5 \\
11\end{array}$ & $\begin{array}{r}17 \\
1 \\
11 \\
29\end{array}$ \\
\hline
\end{tabular}

*Jobs without likely exposure to asbestos. 


\section{Discussion}

Although the association of mesothelioma with asbestos exposure is well established, some features of the association are not fully understood. Among the major types of asbestos minerals, crocidolite, chrysotile, and amosite appear to be associated with the development of mesothelioma but anthophyllite has not been clearly implicated as a cause. ${ }^{4}$ The first report of the association of asbestos and mesothelioma showed that $32 / 33(97 \%)$ of the cases had occupational or environmental exposure to crocidolite. ${ }^{1}$ The proportion of people found to be exposed to asbestos in subsequent case series of mesothelioma varies widely. Relatives of cases have reported that from $10 \%$ to $80 \%$ of cases were exposed..$^{12-14}$.

Although some of the variation in the proportion of cases with reported asbestos exposure may be related to the method of interviewing about exposure, other factors may contribute to the discrepancies. Interobserver variability in histological diagnosis of mesothelioma, even among pathologists who have extensive experience with mesothelioma, has been shown. ${ }^{16}$ The inclusion of non-mesothelial tumours in studies of mesothelioma could affect the observed association of mesothelioma with asbestos exposure and the prevalence of causes other than asbestos in the study population is also important. Recent reports have shown that mesothelioma in man is related to exposure to fibrous forms of zeolites, which are non-asbestos minerals. ${ }^{17}$ Reports have also related the occurrence of pleural and peritoneal mesothelioma to chronic inflammatory disease in the absence of a history of previous exposure to asbestos ${ }^{1819}$ and to thorotrast ${ }^{20}$ and radiation exposure. ${ }^{21} 22$

Identification of a histological group of mesotheliomas that indicates a strong association with asbestos exposure would be an important addition to our understanding of mesothelioma. Such a subgroup could be useful for refining response variables for epidemiological studies and would be important in the medical-legal attribution of cause for cases of mesothelioma. Magner and McDonald observed that cases with mesothelioma of the mixed cell type were most likely to be exposed to asbestos (46\% exposed) and to work in jobs associated with heavy asbestos exposure-for instance, insulation and asbestos products manufacturing. ${ }^{7}$ Cases of epithelial and mesenchymal tumours were less likely to be exposed (9\% and $14 \%$ exposed respectively). They suggested that the mixed cell type of mesothelioma may be expecially related to asbestos exposure.

Our data do not support the hypothesis that the mixed cell type of mesothelioma is more likely to be associated with asbestos exposure than the epithelial and mesenchymal cell types. The proportions of exposed cases in our study were nearly equal for the epithelial and mixed cell types. The distribution of jobs according to cell type in our study also differed from the pattern Magner and McDonald observed: the one man who worked in insulation had a mixed cell tumour but people with epithelial mesotheliomas were more likely than those with the mixed cell type to have worked in asbestos production and manufacturing. Another recent study of mesothelioma used questionnaires and measurement of fibres in pulmonary tissue to estimate exposure to asbestos ${ }^{23}$ and most (15/22, 68\%) cases with epithelial tumours were considered to have been exposed to asbestos. The two cases of fusiform mesothelioma and at least three of the four cases of mixed cell tumours were also considered to have been exposed. These data are consistent with our findings.

In our small number of cases no pattern in proportion of cases exposed or in types of jobs is found that supports the hypothesis that any cell type of mesothelioma is especially related to asbestos exposure. Studies of larger numbers of cases with a more accurate estimate of exposure to asbestos might confirm whether this observation applies to other cases of mesothelioma and to subcategories of the three major histological types of the tumour.

This work was supported by the American Cancer Society (grant SIG-1), the National Cancer Institute (grant PO-1 CA17054), and the Hastings Foundation.

\section{References}

'Wagner JC, Sleggs CA, Marchand P. Diffuse pleural mesothelioma and asbestos exposure in the North Western Cape Province. Br J Ind Med 1960;17:260-71.

${ }^{2}$ Newhouse ML, Thompson H. Mesothelioma of the pleural and peritoneum following exposure to asbestos in the London area. Br J Ind Med 1965;22:261-9.

${ }^{3}$ McDonald AD, Harper A, El Attar OA, McDonald JC. Epidemiology of primary malignant mesothelial tumours in Canada. Cancer 1970;26:914-9.

4 Selikoff IJ, Lee DHK. Asbestos and disease. New York; Academic Press, 1978. [Proportion of deaths in exposed work groups pp 290-2 proportion exposed 40-80\% p 260.]

5 Hourihane DO'B. The pathology of mesotheliomata and an analysis of their association with asbestos exposure. Thorax 1964;19:268-78.

- Antman KH. Malignant mesothelioma. N Engl J Med 1980;303:200-2.

7 Magner D, McDonald AD. Malignant mesothelial tumourshistologic type and asbestos exposure. N Engl J Med 1972;287:570-1.

Mack TM. Cancer surveillance program in Los Angeles County. 
Natl Cancer Inst Monograph 1977;47:99-101.

9 Wright WE, Sherwin RP, Dickson EA, Bernstein L, Fromm JB, Henderson BE. Malignant mesothelioma: incidence, asbestos exposure and reclassification of histopathology. $\mathrm{Br} \mathrm{J}$ Ind $\mathrm{Med}$ 1984;41:39-45.

${ }^{10}$ McDonald AD. Mesothelioma registries in identifying asbestos hazards. Ann NY Acad Sci 1979;330:441-54.

"McDonald AD, McDonald JC. Malignant mesothelioma in North America. Cancer 1980;46:1650-6.

12 Rubino GF, Scansetti G, Donna A, Palestro G. Epidemiology of pleural mesothelioma in north-western Italy (Piedmont). Br J Ind Med 1972;29:436-42.

${ }^{13}$ McEwen J, Finlayson A, Mair A, Gibson AAM. Mesothelioma in Scotland. Br Med J 1970;4:575-78.

14 Whitwell F, Rawcliffe RM. Diffuse malignant pleural mesothelioma and asbestos exposure. Thorax 1971;26:6-22.

is Planteydt HT. Experiences with observer variation in mesothelioma panels. In: Wagner JC, ed. Biological effects of mineral fibres. Vol I. Lyon: International Agency for Research on Cancer, 1980:211-6. (IARC sci pubs No 30.)

${ }^{16}$ McCaughey WTE, Al-Jabi M, Kannerstein M. A Canadian experience of the pathological diagnosis of diffuse mesothelioma. In: Wagner JC, ed. Biological effects of mineral fibres. Vol 1. Lyon: International Agency for Research on Cancer, 1980:207-10. (IARC sci pub No 30.)

${ }^{17}$ Baris YT, Sahin AA, Ozesmi M, et al. An outbreak of pleural mesothelioma and chronic fibrosing pleurisy in the village of Karain/Urgup in Anatolia. Thorax 1978;33:181-92.

${ }^{18}$ Riddell RH, Goodman MJ, Moossa AR. Peritoneal malignant mesothelioma in a patient with recurrent peritonitis. Cancer 1981;48:134-9.

${ }^{19}$ Roviaro GC, Sartori F, Calabro F, Varoli F. The association of pleural mesothelioma and tuberculosis. Am Rev Respir Dis 1982; 126:569-71.

${ }^{20}$ Maurer R, Egloff B. Malignant peritoneal mesothelioma after cholangiography with thorotrast. Cancer 1975;36:1381-5.

${ }^{21}$ Babcock TL, Powell DH, Bothwell R. Radiation induced peritoneal mesothelioma. J Surg Oncol 1976;8:369-72.

22 Stock RJ, Fu YS, Carter JR. Malignant peritoneal mesothelioma following radiotherapy for seminoma of the testis. Cancer 1979;44:914-9.

${ }^{23}$ Hirsch $\mathrm{A}$, Brochard $\mathrm{P}$, DeCremoux $\mathrm{H}$, et al. Features of asbestos-exposed and unexposed mesothelioma. American Journal of Industrial Medicine 1982;3:413-22. 